\title{
Menerapkan Keteladanan Yesus sebagai Guru berdasarkan Injil Lukas bagi Guru SMA Kristen Adhi Wiyata Jember
}

\author{
Nelly $^{1 *}$, Lican Gultom ${ }^{2}$ \\ ${ }^{1}$ Sekolah Tinggi Alkitab Jember, Jember, Jawa Timur \\ ${ }^{2}$ Gereja Pantekosta di Indonesia Ekklesia, Jember, Jawa Timur \\ *jbcnelly@yahoo.co.id
}

\begin{abstract}
The example of a teacher is very important in the world of education. This is because the teacher's example influences the learner's personality or character. The Gospel of Luke is one of the books that was deleted about Jesus' example as a teacher. In His ministry as a teacher, Jesus' example appears from how to teach, train, send, pray, hold on to the scriptures, serve wholeheartedly, thank you and be faithful. As a teacher, He not only teaches theory, but all who do also carry out His research every day. Modeling must be permanent and consistent. The purpose of this article is to describe Jesus' example as a teacher based on the Gospel of Luke and how the teachers applied it. By asking for qualitative, this research applies a descriptive method to Adhi Wiyata Jember Christian High School teachers. The conclusion is that teaching has become the main task of a teacher, but not just cognitive knowledge, but rather the exemplary life as Jesus taught in the Gospel of Luke, so that it brings changes to students and looks for others.
\end{abstract}

Keywords: Teacher, The Gospel of Luke, Jesus' example.

\begin{abstract}
Abstrak: Keteladanan seorang guru sangat penting dalam dunia pendidikan. Hal ini dikarenakan keteladanan guru memengaruhi kepribadian atau watak peserta didik. Injil Lukas merupakan salah satu kitab yang mencatat tentang keteladanan Yesus sebagai guru. Dalam pelayanan-Nya sebagai guru, teladan Yesus tampak dari cara mengajar, melatih, mengutus, berdoa, berpegang pada kitab suci, melayani sepenuh hati, kasih dan setia. Sebagai guru, Ia tidak hanya mengajar secara teori, namun semua yang diajarkan juga ditunjukkan melalui perbuatan-Nya setiap hari. Keteladanan harus bersifat permanen dan konsisten. Tujuan dari artikel ini adalah mendeskripsikan keteladanan Yesus sebagai guru berdasarkan Injil Lukas dan bagaimana para guru mengaplikasikannya. Dengan pendekatan kualitatif, penelitian ini menerapkan metode deskriptif pada guru-guru SMA Kristen Adhi Wiyata Jember. Kesimpulannya adalah mengajar sudah menjadi tugas utama dari seorang guru, tetapi bukan hanya berfokus pada pengetahuan kognitif saja, namun lebih kepada keteladanan hidup seperti yang Yesus ajarkan dalam Injil Lukas, sehingga membawa perubahan perilaku pada murid-murid dan menjadi saksi bagi orang lain.
\end{abstract}

Kata kunci: Guru, Injil Lukas, keteladanan Yesus

\begin{tabular}{llll}
\hline Article History : & Received: 26-05-2020 & Revised: 25-06-2020 & Accepted: 26-06-2020 \\
\hline
\end{tabular}




\section{Pendahuluan}

Pendidikan adalah usaha sadar dan terencana untuk mewujudkan suasana belajar dan proses pembelajaran agar peserta didik secara aktif mengembangkan potensi dirinya untuk memiliki kekuatan spiritual keagamaan, pengendalian diri, kepribadian, kecerdasan, akhlak mulia, serta keterampilan yang diperlukan dirinya, masyarakat, bangsa dan negara. ${ }^{1}$ Jadi pendidikan sebagai salah satu upaya dalam rangka meningkatkan kualitas hidup manusia.

Fungsi dan tujuan pendidikan nasional dalam UU Sisdiknas 2003 pasal 3 adalah mengembangkan kemampuan dan membentuk watak serta peradaban bangsa yang bermanfaat dalam rangka mencerdaskan kehidupan bangsa, bertujuan untuk berkembangnya potensi peserta didik agar menjadi manusia yang beriman dan bertakwa kepada Tuhan Yang Mahaesa, berakhlak mulia, sehat, berilmu, cakap, kreatif, mandiri, dan menjadi warga negara yang demokratis serta bertanggung jawab. ${ }^{2}$ Kondisi riil menunjukkan pembangunan jati diri bangsa semakin memudar yang disebabkan antara lain: kurangnya keteladanan, pemberitaan media cetak dan elektronik yang tidak mendidik, pendidikan belum banyak memberi kontribusi optimal dalam pembentukan karaktek peserta didik.

Dalam dunia pendidikan hal yang paling utama adalah peran seorang guru sebagai pengajar, pendidik, dan juga agen pembaharuan. Berdasarkan UU No. 14 Tahun 2005, guru adalah pendidik profesional dengan tugas utama mendidik, mengajar, membimbing, mengarahkan, melatih, menilai, dan mengevaluasi peserta didik pada pendidikan anak usia dini jalur pendidikan formal, pendidikan dasar, dan pendidikan menengah. ${ }^{3}$ Jadi guru mempunyai peran penting sebagai penentu keberhasilan tujuan pendidikan.

Kehadiran guru dalam proses pembelajaran sebagai sarana mewariskan nilai-nilai dan norma-norma masih memegang peranan yang sangat penting. Peranan guru dalam pembelajaran tidak bisa digantikan oleh hasil teknologi modern seperti kompoter dan lainnya. Guru merupakan salah satu komponen yang penting dalam sistem pengajaran, karena guru mempunyai fungsi mengajar, mencerdaskan, mempertanggung jawabkan, melindungi, mengasuh, mengasah, dan mengasihi di sekolah. ${ }^{4}$ Tanggung jawab guru adalah membantu peserta didik agar dapat mengembangkan potensi yang dimilikinya secara maksimal. ${ }^{5}$

\footnotetext{
${ }^{1}$ Definisi pendidikan berdasarkan Undang-Undang RI Nomor 20 Tahun 2003 tentang Sisdiknas, Pasal 1 ayat (1).

2Undang-Undang RI No. 20 Tahun 2013 tentang Sisdiknas Bab II Pasal 3.

3Undang-Undang RI No. 14 Tahun 2005 tentang Guru dan Dosen Bab I Pasal 1.

${ }^{4}$ S. Vianita Zulyan, Berchah Pitoewas, M. Mona Adha, "Pengaruh Keteladanan Guru Terhadap Sikap Belajar Peserta Didik," Jurnal Kultur Demokrasi 2, no. 2 (2014): 1-12, http://jurnal.fkip.unila.ac.id/index.php/JKD/article/viewFile/4208/2629.

${ }^{5}$ Esther Rela Intarti, "Peran Guru Pendidikan Agama Kristen Sebagai Motivator," Jurnal Pendidikan Agama Kristen Regula Fidei 1, no. 2 (2016): 28-40, http://christianeducation.id/ejournal/index.php/regulafidei/article/viewFile/12/12.
} 
Itulah sebabnya guru memiliki peran yang sangat penting dalam mencerdaskan bangsa. Menurut Cahyadi, guru merupakan satu diantara pembentuk-pembentuk utama calon warga masyarakat. ${ }^{6}$ Guru dan peserta didik merupakan faktor penentu yang sangat dominan dalam pendidikan umumnya, karena guru dan peserta didik memegang peranan dalam proses pembelajaran, di mana proses pembelajaran merupakan inti dari proses pendidikan secara keseluruhan yang bertujuan terjadinya perubahan tingkah laku anak. ${ }^{7}$ Guru diharapkan bisa mengembalikan peradaban bangsa yang tinggi, yang selama ini telah tergantikan dengan julukan bangsa yang korup, tidak memiliki kepribadian, bangsa yang kacau, jorok, bodoh, anarkis dan banyak atribut jelek lainnya yang kini melekat pada bangsa tercinta ini. ${ }^{8}$

Guru mejadi sentral keteladanan sewaktu anak masih menjadi murid. Dengan kata lain, semua ucapan dan tingkah laku guru selalu menjadi perhatian muridnya, dijadikan pedoman dan selalu ditiru oleh muridnya, bahkan bisa jadi mengalahkan pengaruh orang tua di rumah. ${ }^{9}$ Guru dapat diartikan sebagai orangtua kedua, guru harusnya memperlakukan setiap siswa sebagai anaknya sendiri. ${ }^{10}$

Dalam pandangan agama Kristen, seorang guru Kristen baik sebagai guru yang mengajarkan pelajaran Agama Kristen maupun sebagai guru yang mengajarkan pelajaran umum, ia harus memerhatikan bahwa mengajar itu merupakan amanat atau perintah Tuhan. ${ }^{11}$ Salah satu peran Guru Agama Kristen adalah mendidik dan mengajar sesuai dengan nilai-nilai yang berlaku dalam masyarakat. ${ }^{12}$ Peranan guru Agama Kristen sangat berguna dalam perubahan karakter dan perilaku anak. ${ }^{13}$ Guru Pendidikan Agama Kristen sebagai pendidik bertugas memperlengkapi anak didik dengan berbagai kebutuhan agar

6Rahman Cahyadi, "Hubungan antara Motivasi Belajar Siswa dan Penampilan Guru terhadap Hasil Belajar Siswa," e-DuMath Jurnal Pendidikan Matematika 2, No. 2 (2016): 233-245, https://ejournal.umpri.ac.id/index.php/edumath/article/view/187.

${ }^{7}$ Askhabul Kirom, "Peran Guru dan Peserta Didik dalam Proses Pembelajaran Berbasis

Multikultural," Al-Murabbi: Jurnal Pendidikan Agama Islam 3, no. 1 (2017): 69-80,

https://jurnal.yudharta.ac.id/v2/index.php/pai.

8Marsi Bombongan Rantesalu, "Guru Pendidikan Agama Kristen Sebagai Pelopor Revolusi

Mental," Arrang Jurnal Pendidikan Agama Kristen 4, no. 1 (2017): 61-72,

https://osf.io/preprints/agrixiv/576qt.

9Samino, "Urgensi Guru Sejati di Sekolah Dasar," Profesi Pendidikan Dasar 1, no. 1 (2014): 31-41, http://journals.ums.ac.id/index.php/ppd/article/viewFile/1553/1093.

${ }^{10}$ Diana Rotua Silaban, "Peran Guru Pendidikan Agama Kristen Sebagai Konselor bagi Perubahan Perilaku Remaja Kelas X-XI di Sma Negeri 48 Jakarta Timur," Jurnal Pendidikan Agama Kristen Regula Fidei 3, no. 1 (2018): 459-481, http://ejournal.uki.ac.id/index.php/regulafidei/article/view/979/798.

11I Putu Ayub Darmawan, Menjadi Guru yang Terampil (Bandung: Kalam Hidup, 2014), 3.

${ }^{12}$ Talizaro Tafonao, "Peran Guru Agama Kristen dalam Membangun Karakter Siswa di Era Digital," Jurnal Bijak 2, no. 1 (2018): 1-37, https://osf.io/preprints/agrixiv/4ms3g.

${ }^{13}$ Lilis Ermindyawati, "Peranan Guru Pendidikan Agama Kristen Terhadap Perilaku Siswa-Siswi," FIDEI: Jurnal Teologi Sistematika dan Praktika 2, no. 1 (2019): 40-61, https://core.ac.uk/download/pdf/235055841.pdf. 
bertumbuh di dalam Yesus Kristus. ${ }^{14}$ Hal yang sama disampaikan oleh Nainggolan bahwa guru Pendidikan Agama Kristen mempunyai model yang dijadikan sebagai teladan yaitu Yesus Kristus. ${ }^{15}$

\section{Metode Penelitian}

Penelitian ini merupakan penelitian kualitatif yang dilakukan dengan menggunakan metode deskriptif. Artinya, data dan fakta yang dihimpun lebih berbentuk kata atau gambar dari pada angka-angka. Mendeskripsikan yang dimaksud di sini berarti menggambarkan apa, mengapa, dan bagaimana suatu kejadian terjadi. ${ }^{16}$ Penelitian dilakukan dalam dua tahapan dalam pengumpulan data, yaitu: pengumpulan data awal dan pengumpulan data utama. Pengumpulan data awal dilakukan melalui observasi, yaitu metode pengamatan yang mengharuskan peneliti turun ke lapangan mengamati hal-hal yang berkaitan dengan subyek penelitian. Sementara metode pengumpulan data utama yang digunakan dalam penelitian ini, yaitu melalui wawancara terstruktur kepada lima orang guru SMA Adhi Wiyata Jember.

Wawancara terstruktur yang dilakukan oleh peneliti ini diketahui secara jelas dan terperinci informasi yang dibutuhkan dan memiliki satu daftar pertanyaan yang sudah ditentukan atau disusun sebelumnya yang akan disampaikan kepada responden. ${ }^{17}$ Peneliti memiliki sejumlah pertanyaan yang telah disusun dan mengadakan wawancara atas dasar atau panduan pertanyaan tersebut.

Metode deskriptif digunakan juga untuk memberikan gambaran tentang keteladanan Yesus sebagai guru menurut Injil Lukas lalu setelah dianalisis akan diterapkan pada guru-guru SMA Kristen Adhi Wiyata Jember.

\section{Hasil dan Pembahasan}

Injil Lukas adalah salah satu dari empat Injil yang mengawali Perjanjian Baru. kitab ini digolongkan sebagai Injil Sinoptik bersama dengan Injil Matius dan Markus. Isi pemberitaannya mengenai kehidupan dan pelayanan Yesus. ${ }^{18}$ Kitab ini digolongkan sebagai Injil Sinoptik karena diperkirakan penyusunan Injil Lukas menggunakan bahanbahan tulisan yang hampir sama dengan yang digunakan dalam Injil Matius dan Injil Markus, tetapi hasil susunannya tidak persis sama dengan kedua Injil tersebut. ${ }^{19}$

\footnotetext{
${ }^{14}$ Arozatulo Telaumbanua, "Peranan Guru Pendidikan Agama Kristen dalam Membentuk Karakter Siswa," FIDEI: Jurnal Teologi Sistematika dan Praktika 1, no. 2 (2018): 219-231, https://core.ac.uk/download/pdf/235055851.pdf.

15John M. Nainggolan, Guru Agama Kristen sebagai Panggilan dan Profesi (Bandung: Media Informasi, 2010), 3-9.

16Djaman Satori dan Aan Komariah, Metodologi Penelitian Kualitatif (Bandung: Alfabeta, 2010), 28.

17Ulber Silalahi, Metode Penelitian Sosial (Bandung: PT. Refika Aditama, 2009), 313.

${ }^{18}$ Samuel Benyamin Hakh. Perjanjian Baru: Sejarah, Pengantar dan Pokok-pokok Teologisnya (Bandung: Bina Media Informasi, 2010), 268.

${ }^{19}$ S. Wismoady Wahono, Di sini Kutemukan (Jakarta: BPK Gunung Mulia, 1986), 376.
} 
Injil Lukas adalah Injil yang paling lengkap dibandingkan kitab Injil yang lain yang mencatat tentang kehidupan Yesus selama Ia di dunia. Eferett F. Harrison mengatakan, "Injil menurut Lukas merupakan kisah paling lengkap tentang kehidupan Yesus yang masih bertahan sejak zaman rasuli. Injil ini dimaksudkan sebagai suatu penyajian lengkap tentang karier sang Juruselamat sejak lahir hingga kenaikan-Nya, dan merupakan bagian dari karya yang lebih besar termasuk Kisah Para Rasul, yang meneruskan sejarah itu menjadi kegiatan misioner gereja sampai pendirian masyarakat Kristen di Roma."20 Di samping itu Injil Lukas ditulis berdasarkan pengamatan yang cermat mengungkapkan bobot penulisan sejarah Injil itu ditulis dalam bentuk yang teratur, rapi dan menyeluruh. ${ }^{21}$

\section{Keteladanan Guru Kristen}

Kata keteladanan berasal dari kata teladan yang dalam Kamus Besar Bahasa Indonesia berarti "perbuatan yang patut ditiru, dicontoh." Sedangkan kata "keteladanan" diartikan "hal-hal yang dapat ditiru atau dicontoh."22 Kata "teladan" dalam bahasa Yunani berasal dari kata $v \bar{\pi} \mathrm{o}, \delta \varepsilon \imath \gamma \mu \alpha$ (hupodeingma) yang diterjemahkan "teladan, contoh, tiruan."23

Keteladanan adalah hasil dari tindakan proses ketaatan dan ketekunan akan Firman Tuhan. Orang dikatakan teladan bila ia sudah melakukan hal yang benar dan berdampak positif bagi orang lain. Hal ini berlaku apakah dia berada maupun tidak bersama orang-orang yang meneladaninya. Keteladanan harus bersifat permanen/tetap dan konsisten. Oleh sebab itu, keteladanan saling berkaitan dengan kedewasaan rohani. Orang dewasa rohani adalah orang yang punya integritas dan selalu berusaha untuk "berbuah" rohani.

Jamal Asmani menulis, keteladanan guru merupakan faktor mutlak pendidikan karena keteladanan lahir dari proses pendidikan yang panjang, mulai dari pengayaan materi, perenungan, penghayatan, pengamalan, ketahanan, hingga konsistensi dalam aktualisasi. ${ }^{24}$ Gurulah yang pertama-tama harus memiliki pribadi yang mantap, yang memungkinkannya menjalankan tugas keguruan sejati. Beratnya beban yang ada di pundaknya tidak akan terasa bilamana guru memiliki sikap batin yang benar dalam

${ }^{20}$ Charles F. Pfeiffer \& Everett F. Harrison, Tafsiran Alkitab Wycliffe, Volume 3 (Malang: Gandum Mas, 2013), 213.

21J.D. Douglas, Ensiklopedi Alkitab Masa Kini, Jilid Satu (Jakarta: Yayasan Komunikasi Bina Kasih/OMF, 2008), 653.

${ }^{22}$ Tim Penyusun Kamus Pusat Bahasa, Kamus Besar Bahasa Indonesia (Jakarta: Balai Pustaka, 2001), 1160.

${ }^{23}$ Hasan Sutanto, Perjanjian Baru Interlinear Yunani-Indonesia dan Konkordansi Perjanjian Baru II (Jakarta: LAI, 2004), 780.

${ }^{24}$ Jamal Ma'mur Asmani, Buku Panduan Internalisasi Pendidikan Karakter di Sekolah (Jogjakarta: Diva Press, 2011), 74-75. 
menerima tugas itu, yakni "jika dalam sanubari guru terpatri jiwa pengabdian yang tulus, kecintaan terhadap anak bangsa, dan tanggung jawab kepada bangsanya."25

Gagasan tentang keteladanan guru Kristen ditemukan secara kuat dalam dua terminologi Alkitab yang terikat satu dengan yang lain, yakni "guru" dan "murid." "Murid" adalah salah satu istilah yang paling sering digunakan untuk menyebut identitas Kristen. Bahkan, istilah "murid" justru jauh lebih banyak digunakan Alkitab untuk mengidentifikasi pengikut Kristus dibandingkan istilah "Kristen." Sementara itu orang Kristen juga mengenal dan mengakui peran-peran guru dalam komunitasnya. Namun, di atas semua guru ada "Guru Agung" yaitu Yesus Kristus. Kepada-Nyalah berguru semua guru dan murid. Pazmino mengatakan, "For Christians, Jesus alone stands as the Master Teacher, as the exemplar or model for teaching whose life and ministry are worthy of passionate consideration and emulation." 26

\section{Keteladanan Yesus sebagai Guru berdasarkan Injil Lukas}

Keteladanan Yesus sebagai guru terlihat dari kehadiran-Nya dalam pengajaran. Pengajaran yang disampaikan Yesus bagi murid dan pendengar-Nya mampu membawa perubahan hidup (Luk. 19:1-10). Keteladanan yang diperlihatkan Yesus dalam Injil Lukas tampak sangat jelas melalui pedagogi, spiritual dan integritas-Nya.

\section{Pedagogi Yesus}

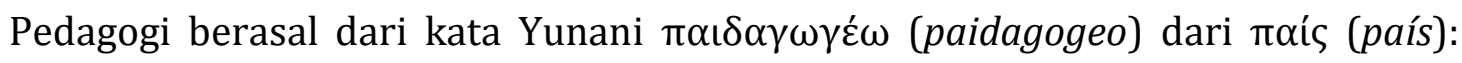
anak dan ó $\gamma \omega$ (ági): membimbing; secara literal berarti "membimbing anak"). Di Yunani Kuno, kata $\pi \alpha \iota \delta \alpha \gamma \omega \gamma o ́ s$ (paidagogos) biasanya diterapkan pada budak yang mengawasi pendidikan anak tuannya. Termasuk di dalamnya mengantarnya ke sekolah

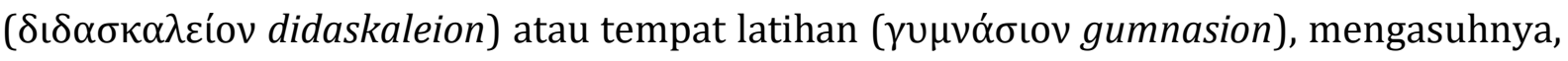
dan membawakan perbekalan. Pedagogi adalah ilmu yang mempelajari masalah membimbing anak ke arah tujuan tertentu, yaitu supaya ia kelak mampu secara mandiri menyelesaikan tugas hidupnya. Dengan demikian pedagogi menekankan pada kegiatan mendidik dan membimbing anak. ${ }^{27}$

Pedagogi Yesus dalam Injil Lukas terdiri dari mengajar, melatih dan mengutus. Yesus mengajar di kota dan desa (Luk. 8:1), rumah ibadat (Luk. 4:16; 6:6), rumah (Luk. 10:38-42) dan di atas bukit (Luk. 6:17-26). Hal ini menunjukkan bahwa Yesus sangat mengutamakan pekerjaan mengajar. Ia selalu menggunakan kesempatan untuk mengajar semua orang tanpa membedakan usia, gender, budaya dan pendidikan seseorang (Luk. 4:31-37, 42-44; 6:17-49; 10:1-16, 38-42; 11:37-54; 12:1-59; 13:10-35; 15-20). Seperti

${ }^{25}$ M. Nurdin, Pendidikan yang Menyebalkan (Jogjakarta: Ar-Ruzz, 2005), 30-31.

${ }^{26}$ Robert W. Pazmino, God Our Teacher: Theological Basics in Christian Education (Grand Rapids Michigan: Baker Academic, 2001), 59.

${ }^{27}$ Jonar Situmorang, Kode Etik \& Profesionalitas Guru PAK (Jember: STAJ, 2019), 26. 
yang diungkapkan oleh J.M. Price, Yesus tepat sekali bagi pekerjaan mengajar dan tidak ada orang yang lebih tepat untuk tugas ini dari pada Yesus. ${ }^{28}$

Kuasa dan keahlian yang dimiliki Yesus dalam mengajar menjadi daya tarik bagi banyak orang (Luk. 4:31-37; 5:17). Oleh sebab itu banyak orang datang dan mencarinya untuk mendengarkan pengajaran-Nya. Pengajaran yang disampaikan Yesus tidak sekedar teori yang membuat pendengar-Nya hanya sebatas mengetahui, melainkan pengajaran Yesus membawa kepada perubahan hidup. Jadi, mengajar merupakan bagian penting dari seorang guru dan membawa pada perubahan perilaku.

Selanjutnya, Yesus juga melatih murid-murid-Nya. Yesus menyadari untuk menjadi murid yang berhasil dan tangguh, harus menjalani latihan. Mulyasa mengatakan pembelajaran memerlukan latihan keterampilan, baik intelektual maupun motorik hingga menuntut guru untuk bertindak sebagai pelatih. ${ }^{29}$ Pelatihan yang diberikan Yesus yaitu murid terlibat langsung di lapangan, contoh ketika Yesus memberi makan lima ribu orang, Yesus melibatkan langsung murid-Nya menghadapi masalah kekurangan makan saat itu (Luk. 9:1017; 8:22-25). Untuk melatih murid-Nya, Yesus dihadapkan dengan berbagai tantangan. Yesus harus melihat kegagalan (Luk. 22:54-62) dan adanya konflik di antara murid-murid (Luk. 9:46-48). Tetapi Yesus mampu mengatasi persoalan yang dialami murid-murid. Dengan adanya masalah yang dihadapi, Yesus mengajarkan nilainilai baru kepada murid-Nya. Jadi, tujuan Yesus melatih murid-murid-Nya adalah terpusat pada transformasi (Luk. 6:39-40). Maksudnya adalah supaya murid-Nya dapat melihat secara langsung ajaran Tuhan Yesus terwujud dalam hidup manusia dan di dalam bermacam-macam situasi.

Sesudah Yesus mengajar dan melatih, maka selanjutnya adalah mengutus muridmurid. Lukas mencatat bagaimana Yesus mengutus murid-murid ke setiap kota memberitakan tentang kerajaan Allah sudah dekat (Luk. 10:1-12). Pengutusan adalah salah satu tujuan pengajaran Yesus. Ia tahu bahwa tidak selamanya ada di dunia. Oleh sebab itu Yesus mengajar dan melatih murid-murid-Nya untuk menjadi penerus dalam memberitakan serta mengajarkan Injil.

\section{Spiritual Yesus}

Dalam Injil Lukas, spiritual Yesus terlihat jelas pada kehidupan-Nya yaitu tekun dalam berdoa, berpegang pada kitab suci dan melayani sepenuh hati.

Lukas mencatat dengan jelas doa yang diucapkan Yesus. Lukas mencatat kata Yesus berdoa sebanyak dua belas kali (Luk. 3:21; 5:16; 6:12; 9:18; 9:28; 9:29; 11:1; 22:40, $41,44,45,46)$. Lukas memakai kata eroto $(\mathrm{\rho} \rho \tau \omega)$ untuk kata berdoa. Kata ini adalah kata-kata yang diucapkan Yesus dalam doa-Nya. Yesus adalah seorang guru yang

${ }^{28}$ J.M. Price, Yesus Guru Agung (Bandung: Literatur Baptis, 2011), 15.

${ }^{29}$ H.E. Mulyasa, Menjadi Guru Profesional, 42. 
berdoa. ${ }^{30}$ Doa menjadi bagian yang inti dalam hidup Yesus dan menjadi kegiatan rutin yang dilakukan Yesus. Kegiatan Yesus untuk selalu berdoa merupakan satu bukti nyata kedekatan Yesus dengan Bapa. Yesus menyadari untuk melakukan pelayanan yang ditugaskan Bapa, membutuhkan pimpinan dan kekuatan dari Bapa.

Barclay menyebut Injil Lukas adalah Injil doa, Lukas memperlihatkan kepada pembacanya bagaimana Yesus dalam menghadapi saat-saat penting dalam hidup-Nya, Ia berdoa. ${ }^{31}$ Lukas mencatat beberapa doa Yesus. Biasanya doa-doa yang dilakukan Yesus terkait dengan peristiwa-peristiwa penting, diantaranya: pada saat dibaptis (Luk. 3:21), sebelum bertentangan dengan orang-orang Farisi setelah mengadakan mujizat-mujizat (Luk. 5:16), sebelum memilih murid-murid-Nya (Luk. 6:16), sebelum pemberitahuan pertama sekali tentang akan penderitaan-Nya (Luk. 9:18-22), pada saat dimuliakan (Luk. 9:29), kembalinya ketujuh puluh murid (Luk. 10:17-21). Hanya Lukas yang menceritakan mengenai doa dalam perumpamaan sahabat pada tengah malam (Luk. 11:5-13). Ia juga berbicara tentang berdoa pada perumpamaan hakim yang tidak adil (Luk. 18:1-8), mengajarkan tentang perumpamaan tentang doa yang dilakukan oleh orang Faris dan pemungut cukai di bait Allah (Luk. 18:9-14), di taman Getsemani (Luk. 22:39-46), di atas kayu salib (Luk. 23:46) dan Yesus berdoa bagi Petrus pada saat mengalami pencobaan (Luk. 22:23).

Selain tekun dalam berdoa, Yesus memberi teladan dalam hal berpegang pada kitab suci. Yesus percaya bahwa Alkitab adalah Firman Allah. Ini terbukti saat Iblis datang mencobai-Nya untuk menghentikan pelayanan dan misi-Nya, untuk mengalahkan kekuatan Iblis, Yesus mengutip Firman Tuhan. Lukas mencatat berbagai peristiwa yang menunjukkan bahwa Yesus bergaul akrab dengan Firman Tuhan di antaranya: Yesus mendengarkan Firman Tuhan (Luk. 2:46), membaca Firman Tuhan (Luk. 4:16), menghafal Firman Tuhan (Luk. 11:29-30), menyelidiki Firman Tuhan dan mempraktekkan Firman Tuhan (Luk. 8:20-21, 11:27-28). Jadi Yesus hidup berdasarkan Firman Tuhan yaitu menggunakan Firman sebagai suatu yang penting dalam hidup-Nya.

Berikutnya, Yesus melayani sepenuh hati. Ia tidak pernah melakukan pelayanan karena terpaksa. Yesus menyadari pelayanan yang dikerjakan adalah bagian dari melakukan kehendak Bapa (Luk. 3:22). Demikian pula dalam hal mengajar merupakan pelayanan Yesus yang utama dan Ia sungguh-sungguh dalam pengajaran-Nya. Susanto dalam tulisannya mengatakan "komitmen-Nya sangat kuat untuk melayani segenap hati agar anggotanya mencapai hasil maksimal, berbuah banyak serta bersama-sama

\footnotetext{
${ }^{30}$ Kegiatan Yesus berdoa juga dicatatat oleh ketiga penulis Injil sinoptik lainnya (Mat. 14:2326:36; 26:39; Mrk. 1:35; 6:46; 14:32; 14:35; Luk. 3:21; 5:16; 6:12; 9:18; 9:28-29; 23:32; 22:41). Hal ini menunjukkan doa Yesus menjadi perhatian penting bagi para penulis Injil.

31William Barclay, Pemahaman Alkitab Setiap Hari Lukas, (Jakarta: BPK Gunung Mulia, 2009), 5.
} 
mencapai kemenangan." ${ }^{22}$ Nainggolan mengatakan, dengan segenap hati Yesus bergumul dan berjuang menyampaikan kebenaran. ${ }^{33}$

\section{Integritas Yesus}

Integritas adalah kesesuaian antara perkataan dan perbuatan secara konsisten sebagai buah dari kedekatan dengan Allah. Yesus sebagai Guru mempunyai gaya hidup yang sesuai dengan apa yang Ia ajarkan. Ia mengajar bukan hanya dengan kata-kata yang manis dan bombastis atau muluk-muluk seperti para rabi Yahudi, tetapi pengajaran-Nya disertai dengan perbuatan yang sesuai dengan ajaran-Nya. ${ }^{34}$ Apapun yang la katakan dan ajarkan itulah yang Ia lakukan.

Integritas Yesus dalam Injil Lukas nampak pada kasih dan setia. Teladan Yesus yang paling menonjol adalah kasih-Nya. Segala sesuatu yang dikerjakan-Nya jelas semua hanya karena kasih. Lukas mencatat bahwa Yesus adalah kasih (Luk. 2:40). Kasih yang ditunjukkan Yesus lewat pelayanan-Nya membuktikan bahwa Ia adalah kasih (Luk. $6: 27,35 ; 7: 13 ; 10: 25-37 ; 17: 13 ; 18: 38)$. Artinya setiap pelayanan yang dikerjakan Yesus tidak mengharapkan imbalan atau pujian dari manusia. Kasih storge banyak ditekankan Yesus pada Injil Lukas ini (Luk. 10:27b; 6:27,35; 10:30-37). Jadi, kasih yang diajarkan dan dilakukan Yesus membuktikan bahwa Ia adalah pribadi yang berintegritas tinggi.

Selanjutnya adalah setia, khususnya dalam beribadah. Tenney mengatakan, "Yesus menghadiri dan ambil bagian dalam kebaktian di sinagoge secara teratur." 35 Yesus kerap kali datang ke Bait Allah untuk beribadah (Luk. 4:15-16, 31,44; 6:6), mengajar (Luk. 4:15, 21, 31-32; 5:3; 6;6) dan mengikuti perayaan hari-hari raya orang Yahudi (Luk. 2:4151). Kesetiaan Yesus dalam beribadah bukan karena hal itu adalah suatu kewajiban yang harus dilakukan Yesus. Ia beribadah karena Ia menjaga hubungan yang intim dengan Bapa. Setiap waktu yang dilalui, Yesus tidak pernah terlepas dari persekutuan yang dibangunnya dengan Bapa. Hal itu ditunjukkan Yesus dengan kesetiaan datang beribadah ke rumah ibadah. Selain itu kesetiaan yang Injil Lukas catat adalah ketika Yesus selalu meluangkan waktu untuk bersekutu secara pribadi dengan Bapa melalui doa (Luk. 3:21; $5: 16 ; 6: 12 ; 22: 41,44,45)$. Jadi, kesetiaan merupakan hal yang sangat penting dalam kehidupan seorang guru. Sebab hal itu merupakan bukti keyakinan, iman atau kepercayaan seseorang kepada Tuhan. Kesetiaan merupakan kualitas diri seseorang yang tergambar dalam hal seseorang menepati janji dan memenuhi tanggung jawabnya sebagai seorang guru.

${ }^{32}$ Susanto, Meneladani Jejak Yesus Sebagai Pemimpin (Yogyakarta: Andi, 2006), 34

${ }^{33}$ Meily Lunanta, "Pengaruh Pelayanan Remaja Terhadap Pertumbuhan Rohani Remaja Usia 12-15 tahun di GKII Jemaat Antutan Kalimantan Utara," Repository Skripsi Online, 2020 - skripsi.sttjaffray.ac.id.

${ }^{34}$ Daniel Sutoyo, "Yesus Sebagai Guru Agung," Antusias Jurnal Teologi dan Pelayanan 3, no. 5 (2014): 1-27, https://www.sttintheos.ac.id/e-journal/index.php/antusias/article/view/13.

35Merrill C. Tenney, Survey Perjanjian Baru (Malang: Gandum Mas, 2006), 115. 


\section{Mengaplikasikan Keteladanan Yesus Sebagai Guru}

SMA Kristen Adhi Wiyata Jember berdiri pada tahun 1981 di bawah naungan Yayasan Dorkas. Memiliki visi menjadikan peserta didik menjadi insan yang cerdas, berprestasi, berhati mulia dan berbakti dalam semangat kasih doa, persaudaraan dan pelayanan. Adapun tujuan berdirinya SMA Kristen Adhi Wiyata Jember yaitu menjadikan peserta didik jadi insan yang cerdas, berprestasi, berhati mulia dan berbakti dalam semangat kasih doa, persaudaraan dan pelayanan. Tujuan ini sesuai dengan visi SMA Adhi Wiyata Jember. Ibu Estu Andriyani selaku kepala sekolah menyatakan bahwa dengan adanya sekolah ini, maka akan muncul anak-anak yang cerdas, bukan hanya intelektuanya namun perilaku dan rohaninya akan menjadi teladan bagi banyak orang serta bagi sekolah-sekolah lainnya.

Berdasarkan observasi dan wawancara terstruktur pada responden menunjukkan pemahaman para guru SMA Adhi Wiyata Jember dalam keteladanan, namun ada beberapa hal yang perlu diperbaiki, supaya keteladanan yang dimiliki guru-guru lebih baik lagi, maka dirancang aplikasi yang sifatnya terapan dan semoga dapat menjadi usulan untuk dipelajari bersama oleh para guru SMA Adhi Wiyata Jember. Keteladan tersebut dapat dilihat dalam tabel di bawah ini.

\begin{tabular}{|c|c|c|}
\hline No & $\begin{array}{l}\text { Keteladanan Yesus } \\
\text { Berdasarkan Injil } \\
\text { Lukas }\end{array}$ & Aplikasi \\
\hline \multirow{6}{*}{1} & \multirow{6}{*}{ Pedagogi Yesus } & $\begin{array}{l}\text { 1. Guru yang mengajar adalah guru yang } \\
\text { memiliki kuasa, keahlian serta daya tarik } \\
\text { bagi anak didiknya. }\end{array}$ \\
\hline & & $\begin{array}{l}\text { 2. Guru mengajar dengan tujuan perubahan } \\
\text { perilaku anak didik, bukan hanya pada } \\
\text { pengetahuan kognitif. }\end{array}$ \\
\hline & & $\begin{array}{l}\text { 3. Guru melatih anak didik secara langsung } \\
\text { baik dalam materi ajar maupun dalam hal } \\
\text { menyelesaikan masalah pribadi anak } \\
\text { didik. }\end{array}$ \\
\hline & & $\begin{array}{l}\text { 4. Guru melatih anak didik meskipun ada } \\
\text { kesibukan kerja. }\end{array}$ \\
\hline & & $\begin{array}{l}\text { 5. Guru melatih anak didik mendapatkan } \\
\text { nilai-nilai yang baik sesuai dengan firman } \\
\text { Tuhan. }\end{array}$ \\
\hline & & $\begin{array}{l}\text { 6. Seorang guru Kristen menjadi saksi dan } \\
\text { mengutus peserta didiknya untuk } \\
\text { menyaksikan kebaikan Tuhan kepada } \\
\text { orang lain. }\end{array}$ \\
\hline \multirow[t]{2}{*}{2} & \multirow[t]{2}{*}{ Spiritual Yesus } & $\begin{array}{l}\text { 1. Berdoa merupakan } \\
\text { kebergantungan manusia kepada Allah. }\end{array}$ \\
\hline & & 2. Berdoa menjadi kebutuhan setiap waktu. \\
\hline
\end{tabular}




\begin{tabular}{|c|c|c|}
\hline & & $\begin{array}{l}\text { 3. Doa menjadi kekuatan dan alat } \\
\text { komunikasi langsung dengan Tuhan. }\end{array}$ \\
\hline & & $\begin{array}{l}\text { 4. Berpegang pada kitab suci terlihat dari } \\
\text { waktu yang diberikan setiap hari untuk } \\
\text { membaca dan mempelajari Alkitab. }\end{array}$ \\
\hline & & $\begin{array}{l}\text { 5. Tidak mudah menyerah ketika } \\
\text { menghadapi kesulitan hidup. }\end{array}$ \\
\hline & & $\begin{array}{l}\text { 6. Melayani sepenuh hati dibuktikan } \\
\text { mengajar dengan sabar dan menuntun } \\
\text { anak didik sampai mengalami perubahan } \\
\text { perilaku yang benar sesuai Alkitab. }\end{array}$ \\
\hline & & $\begin{array}{l}\text { 7. Melayani sepenuh hati adalah memiliki } \\
\text { komitmen yang kuat dalam mengajar dan } \\
\text { mengarahkan anak didik pada kebenaran } \\
\text { firman Tuhan. }\end{array}$ \\
\hline & & $\begin{array}{l}\text { 1. Kasih terlihat dari selalu memberikan } \\
\text { bantuan kepada siapa saja tanpa } \\
\text { membedakan orang, usia, dan suku. }\end{array}$ \\
\hline & & 2. Menjadi berkat bagi banyak orang. \\
\hline & & $\begin{array}{l}\text { 3. Segala sesuatu yang dikerjakan hanya } \\
\text { untuk memuliakan Tuhan bukan untuk } \\
\text { mendapat pujian dan hormat dari orang } \\
\text { lain. }\end{array}$ \\
\hline 3 & Integritas Yesus & $\begin{array}{l}\text { 4. Semua yang dikerjakan guru bukan } \\
\text { berdasarkan materi, namun murni } \\
\text { pelayanan seperti Yesus lakukan. }\end{array}$ \\
\hline & & $\begin{array}{l}\text { 5. Setia terlihat dari selalu meluangkan } \\
\text { waktu beribadah dan terlibat langsung } \\
\text { dalam kegiatan-kegiatan. }\end{array}$ \\
\hline & & $\begin{array}{l}\text { 6. Saat menghadapi masalah dalam rumah } \\
\text { tangga dan pekerjaan, tetap beribadah } \\
\text { atau bersekutu dengan Tuhan. }\end{array}$ \\
\hline
\end{tabular}

\section{Kesimpulan}

Pendidikan umum maupun pendidikan Kristen sama-sama menekankan pentingnya keteladanan dalam proses dan pencapaian tujuan pelaksanaan pendidikan. Keteladanan Yesus berdasarkan Injil Lukas dapat dilihat pada pedagogi dalam hal mengajar, melatih dan mengutus; spiritualitas dalam hal berdoa, berpegang pada kitab suci dan melayani sepenuh hati; integritas dalam hal kasih dan setia. Hal ini dapat diterapkan pada para guru SMA Adhi Wiyata Jember agar meneladani Yesus dalam pengajaran dan kehidupannya. Untuk itu kepala sekolah perlu mengevaluasi masingmasing guru dan mengadakan seminar tentang pembentukan karakter. 


\section{Referensi}

Asmani, Jamal Ma'mur. Buku Panduan Internalisasi Pendidikan Karakter di Sekolah. Jogjakarta: Diva Press, 2011.

Barclay, William. Pemahaman Alkitab Setiap Hari Lukas. Jakarta: BPK Gunung Mulia, 2009.

Cahyadi, Rahman. "Hubungan antara Motivasi Belajar Siswa dan Penampilan Guru terhadap Hasil Belajar Siswa," e-DuMath Jurnal Pendidikan Matematika 2, No. 2 (2016): 233-245, https://ejournal.umpri.ac.id/index.php/edumath/article/view/187.

Darmawan, I Putu Ayub. Menjadi Guru yang Terampil. Bandung: Kalam Hidup, 2014.

Douglas, J.D. Ensiklopedi Alkitab Masa Kini, Jilid Satu. Jakarta: Yayasan Komunikasi Bina Kasih/OMF, 2008.

Ermindyawati, Lilis. "Peranan Guru Pendidikan Agama Kristen Terhadap Perilaku SiswaSiswi," FIDEI: Jurnal Teologi Sistematika dan Praktika 2, no. 1 (2019): 40-61, https://core.ac.uk/download/pdf/235055841.pdf.

Hakh, Samuel Benyamin. Perjanjian Baru: Sejarah, Pengantar dan Pokok-pokok Teologisnya. Bandung: Bina Media Informasi, 2010.

Intarti, Esther Rela. "Peran Guru Pendidikan Agama Kristen Sebagai Motivator," Jurnal Pendidikan Agama Kristen Regula Fidei 1, no. 2 (2016): 28-40, http://christianeducation.id/ejournal/index.php/regulafidei/article/viewFile/12/12.

Kirom, Askhabul. "Peran Guru dan Peserta Didik dalam Proses Pembelajaran Berbasis Multikultural," Al-Murabbi: Jurnal Pendidikan Agama Islam 3, no. 1 (2017): 69-80, https://jurnal.yudharta.ac.id/v2/index.php/pai.

Lunanta, Meily. "Pengaruh Pelayanan Remaja Terhadap Pertumbuhan Rohani Remaja Usia 12-15 tahun di GKII Jemaat Antutan Kalimantan Utara," Repository Skripsi Online, 2020 - skripsi.sttjaffray.ac.id.

Mulyasa, H.E. Menjadi Guru Profesional. Bandung: Remaja Rosdakarya, 2005.

Nainggolan, John M. Guru Agama Kristen sebagai Panggilan dan Profesi. Bandung: Media Informasi, 2010.

Nurdin, M. Pendidikan yang Menyebalkan. Jogjakarta: Ar-Ruzz, 2005.

Pazmino, Robert W. God Our Teacher: Theological Basics in Christian Education. Grand Rapids Michigan: Baker Academic, 2001.

Pfeiffer, Charles F. \& Everett F. Harrison. Tafsiran Alkitab Wycliffe, Volume 3. Malang: Gandum Mas, 2013.

Price, J.M. Yesus Guru Agung. Bandung: Literatur Baptis, 2011.

Rantesalu, Marsi Bombongan. "Guru Pendidikan Agama Kristen Sebagai Pelopor Revolusi Mental," Arrang Jurnal Pendidikan Agama Kristen 4, no. 1 (2017): 61-72, https://osf.io/preprints/agrixiv/576qt.

Samino. "Urgensi Guru Sejati di Sekolah Dasar," Profesi Pendidikan Dasar 1, no. 1 (2014):31-41, http://journals.ums.ac.id/index.php/ppd/article/viewFile/1553/1093.

Satori, Djaman, dan Aan Komariah. Metodologi Penelitian Kualitatif. Bandung: Alfabeta, 2010.

Silaban, Diana Rotua. "Peran Guru Pendidikan Agama Kristen Sebagai Konselor bagi Perubahan Perilaku Remaja Kelas X-XI di Sma Negeri 48 Jakarta Timur," Jurnal Pendidikan Agama Kristen Regula Fidei 3, no. 1 (2018): 459-481, http://ejournal.uki.ac.id/index.php/regulafidei/article/view/979/798.

Silalahi, Ulber. Metode Penelitian Sosial. Bandung: PT. Refika Aditama, 2009. 
Situmorang, Jonar. Kode Etik \& Profesionalitas Guru PAK. Jember: STAJ, 2019.

Susanto. Meneladani Jejak Yesus Sebagai Pemimpin. Yogyakarta: Andi, 2006.

Sutanto, Hasan. Perjanjian Baru Interlinear Yunani-Indonesia dan Konkordansi Perjanjian Baru II. Jakarta: LAI, 2004.

Sutoyo, Daniel. "Yesus Sebagai Guru Agung," Antusias Jurnal Teologi dan Pelayanan 3, no. 5 (2014): 1-27, https://www.sttintheos.ac.id/ejournal/index.php/antusias/article/view/13.

Tafonao, Talizaro. "Peran Guru Agama Kristen dalam Membangun Karakter Siswa di Era Digital," Jurnal Bijak 2, no. 1 (2018): 1-37, https://osf.io/preprints/agrixiv/4ms3g.

Telaumbanua, Arozatulo. "Peranan Guru Pendidikan Agama Kristen dalam Membentuk Karakter Siswa," FIDEI: Jurnal Teologi Sistematika dan Praktika 1, no. 2 (2018): 219-231, https://core.ac.uk/download/pdf/235055851.pdf.

Tenney, Merrill C. Survey Perjanjian Baru. Malang: Gandum Mas, 2006.

Tim Penyusun Kamus Pusat Bahasa, Kamus Besar Bahasa Indonesia (Jakarta: Balai Pustaka, 2001), 1160.

Undang-Undang RI No. 14 Tahun 2005 tentang Guru dan Dosen.

Undang-Undang RI No. 20 Tahun 2013 tentang Sisdiknas.

Wahono, S. Wismoady. Di sini Kutemukan. Jakarta: BPK Gunung Mulia, 1986.

Zulyan, S. Vianita, and Berchah Pitoewas, M. Mona Adha. "Pengaruh Keteladanan Guru Terhadap Sikap Belajar Peserta Didik," Jurnal Kultur Demokrasi 2, no. 2 (2014):112, http://jurnal.fkip.unila.ac.id/index.php/JKD/article/viewFile/4208/2629. 